\title{
Óscar Collazos, una rueda suelta de la literatura en el carnaval de la muerte
}

Carlos Ernesto García* Foto de ANNIA García

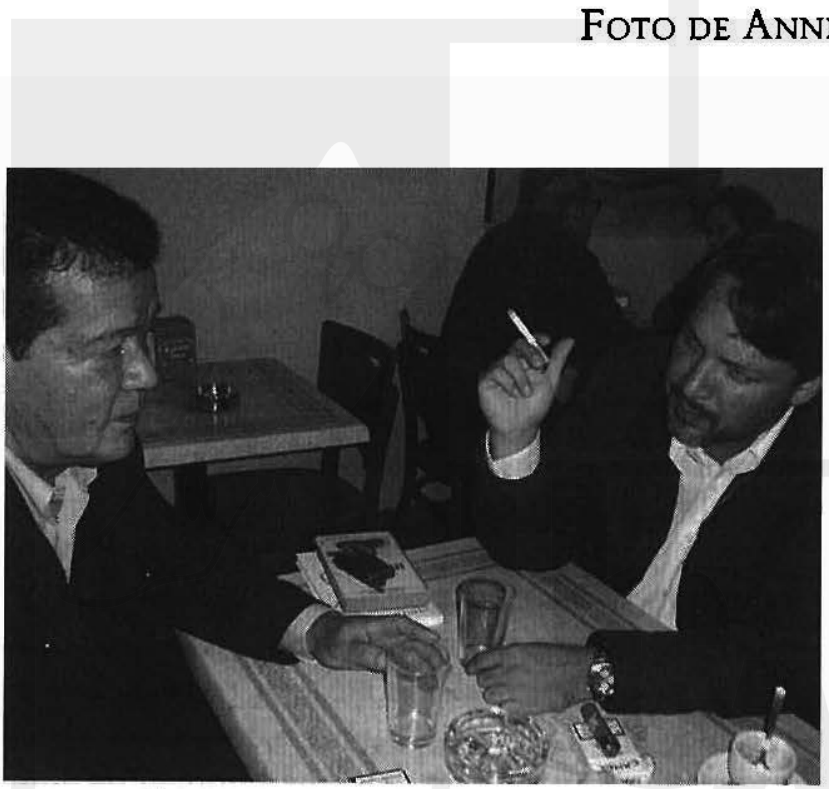

Óscar Collazos y Carlos Ernesto García

De mirada inteligente. Con el hablar pausado que le permite dejar caer las palabras en un lenguaje bien construido y lleno de imágenes. Viajero infatigable, después de varios años, como uno de los personajes de sus novelas, vuelve al lugar del crimen. No nos veiamos desde bacia algo más de quince años. La última vez, si la memoria no me traiciona,

Oscar Collaros, una rueda suetia de la literalura en el carnowal de la muerte 
fue aqui, en Barcelona, al salir una de tantas madrugadas, del único rincón elegante para la salsa que ba existido en esta ciudad: El bikini. Un espacio que nos resguardaba de los golpes de aquella juventud ya lejana $y$, donde boy se levanta un gigantesco centro comercial que alberga restaurantes, cafeterias, librerias, joyerias $y$, tiendas de ropa y de cosmética de las más prestigiosas firmas internacionales.

Autor de novelas y libros de ensayo fundamentalmente, Oscar Collazos publico desde un principio en importantes editoriales tanto en España como en América Latina. Amigo personal de toda una pléyade de autores de reconocido nombre en el mundo de las letras, que van desde Gabriel García Márquez, pasando por Julio Cortázar, Juan Carlos Onetti, Carlos Barral, José Agustín Goytisolo, Sergio Ramírez entre otros, hasta dar, cómo no, con Vargas Llosa de quien, el mismo Collazos confiesa sentirse, al menos en parte, beredero.

Buscamos un pequeño restaurante en el casco antiguo de Barcelona donde poder charlar acompañados de un buen vino tinto. En una de esas callejuelas, en frente mismo de un bar llamado El museo del Whiskey, decidimos que transcurrird esta entrevista mientras poco a poco, con nuestros cigarrillos vamos creando ese clima necesario para evocar viejos tiempos.

¿Que ha sido de tu vida en estos últimos años después de que marchases de Barcelona, donde viviste desde principios de los años setenta?

Bueno, ha corrido mucha agua debajo del molino. Yo regresé a Colombia en mil novecientos ochenta y nueve. Lo último que se publicó en España mío, en Mondadori, fue una novela titulada Fugas y lo curioso es que yo había desaparecido del panorama de la literatura colombiana. Yo era un escritor colombiano, conocido, pero no leído. Escasamente, los libros míos se publicaban en América Latina. Entonces, lo que hice al regresar a Colombia fue, recuperar un espacio que había perdido y, recuperar un país que también de alguna manera había perdido en la memoria. Los cambios sociales y culturales en mí país son tan vertiginosos que, en dieciocho años de ausencia, se habían producido cosas que para mí eran incomprensibles en el espectro político-social. Así pues, era volver a recuperar un país extraviado en mi memoria y también recuperar un espacio editorial. Lo cual conseguí en cierta medida con la reedición de Fugas y ya prácticamente, 
toda la producción siguiente comenzó a ser editada en Colombia y en el resto de América Latina, curiosamente en grandes editoriales españolas, en Alfaguara o en el grupo Planeta. ¿La vida literaria, qué ha sido? Ha sido una vida literaria de tres o cuatro novelas de un género que no lo había abordado desde la perspectiva de libro, sino, del reportaje periodístico. Entonces, publiqué un libro de entrevistas con los candidatos a la presidencia del 2000; edité un libro de ensayos breves que en realidad tenían su origen en el periodismo en una columna que mantuve durante algunos años en la agencia EFE, en la sección Grandes Firmas que circulaba en toda América Latina. Entonces, al regresar a mí país lo que hice fue, continuar lo que había hecho siempre: una actividad literaria paralela a la actividad periodística, fundamentalmente de opinión. Primero en El Espectador y luego en El Tiempo, el periódico de mayor circulación en Colombia.

Nosotros, cuando hablamos de Barcelona y lo hacemos desde América Latina, pensamos en la capitalidad editorial de esta ciudad. La editorial Planeta ahora es un verdadero monstruo que además a absorbido en los últimos años a gran número de editoriales que eran un referente importante para nosotros. Regresar a Colombia para recuperar ese espacio perdido para luego retornar con un libro bajo el brazo que próximamente será publicado en España por la editorial Seix Barral

Sí...es que hay que invertir el mecanismo. Esos monstruos editoriales se inventaron una formula que a la larga ha contribuido a la neo-balcanización en nuestro continente: crear sucursales nacionales; dividir América Latina en cierta áreas y entonces publicar a los escritores de esas áreas exclusivamente en esos países, impidiendo de esta forma, la intercomunicación que existía en los años sesenta y en los años setenta. Entonces, un colombiano sabía lo que se producía en Argentina y un mexicano de lo que se producía en Venezuela o Colombia. Porque aunque sea de una manera quizá un poco precaria, los libros circulaban. Al balcanizar el mercado editorial, resulta que no. Resulta que nos convertimos en celebridades locales y muy escasamente, esos libros pasan a ser reeditados o exportados a otros países. Eso ya lo advertía Carlos Fuentes hacía algunos años, cuando señalaba que ahora Latinoamérica en esta neo-balcanización ha empezado a desconocerse de nuevo. Entonces, solamente nos conocemos los via- 
jeros. El que va a Buenos Aires sabe que una cantidad de escritores que no han entrado en los grandes circuitos internacionales del libro.

Cuando llegas a España, ya habías frecuentado los círculos literarios de Centroamérica. Se guarda la memoria de tu visita en los setenta a El Salvador, donde impartiste una serie de conferencias.

Yo creo que gran parte del interés generacional por mi obra o por lo que pudiera yo decir públicamente arranca de la polémica con Julio Cortázar y Mario Vargas Llosa editada por Siglo XXI: Literatura en la revolución y revolución en la literatura. Esa polémica fue leída fervientemente por escritores jóvenes, es decir, escritores de mi generación, fue debatida en el medio académico y universitario. Entonces cuando se me dio la oportunidad, que por cierto me la ofreció mi amigo Sergio Ramírez, que por esos años no era la gran figura literaria que es hoy, era un escritor de mi generación que había empezado a escribir unos libros importantes en el contexto centroamericano, pero no tenía la proyección que ha tenido en los últimos diez o quince años. Pues, gracias a él hice todo ese periplo que cubrió desde Guatemala hasta Costa Rica. Pero, se daba otro hecho, la gran cercanía que había tenido con otro gran poeta salvadoreño que era Roque Dalton $y$ al año de su muerte, yo visito El Salvador. Y el hecho de haber sido su amigo y de compartir dos años de cercanía en Cuba, en Casa de las Américas, donde tanto él como yo, fuimos miembros del consejo de dirección de esa institución, hizo suponer que yo podría decir algo más de lo que se sabía sobre Roque. $O$ una perspectiva distinta a la perspectiva enrarecida que rodeaba a su personalidad en mil novecientos setenta y seis que fue cuando hice esta gira por Centro América. Entonces, quizá fue eso y la generosidad de mis amigos salvadoreños que me permitió conocer a escritores que después serían mis amigos al cabo de muchos años.

Tú trabajaste durante algún tiempo en televisión y me gustaría saber, cómo se mueve un escritor en un medio como ese en el que, no sólo esta puesta la atención del ciudadano común y corriente, sino el del político. Vamos, que me contaras tu experiencia.

Eso es complicado. Hacer televisión es la cosa más devoradora que pueda haber para un escritor. No me arrepiento de esa experiencia durante un año, pero por fortuna la tuve en un canal cultural y educativo del estado en donde no tenía los altos índices de audiencia. Pero 
para mí, tener tres puntos de reitin significaba que era visto por unos quinientos mil espectadores cada noche. Era un programa de la media noche, es decir, para televidentes murciélagos prácticamente. Era un programa diario y en directo, donde cada día yo debatía un tema y yo tenía a periodistas recorriendo la noche de Bogotá para que hicieran siete minutos de pregrabado que ilustraran ese tema. Fue un año en que yo no pude escribir nada de literatura, salvo lo que escribía en mis columnas de opinión. Desde las siete de la mañana hasta la una y media de la madrugada que salíamos del estudio, prácticamente tenía que estar en función de la televisión. Esa es una madre devoradora, una especie de Saturno. Así que desde entonces comencé a tenerle un gran respeto y un gran miedo a la televisión. Yo no creo que repetiría esa experiencia. Luego hice un programa cultural sobre libros, pregrabado, una sola edición semanal y era igual de devoradora. Lo que sí me permitió es conocer las intimidades del medio, los artificios, el vértigo y acercarme a lo que era también la televisión comercial paralela, que yo creo que es la más alta y sofisticada de las prostituciones de nuestro tiempo.

¿Qué es lo que existe al otro lado de la calle cuando se ve la muerte desde la otra orilla?

Pues es muy contradictorio, al otro lado de la calle existe por supuesto el miedo a la muerte, pero también el enorme dilema entre la preservación de la vida y el instinto temerario. Yo particularmente cuando me he encontrado en situaciones que me han puesto a reflexionar sobre eso he llegado a la conclusión de que no tengo pasta de héroe y que soy un cobarde, que es la única manera de preservar la vida. Así que en ese escenario de Colombia donde no es difícil que alguien esté al otro lado de la acera y mire al frente la muerte, no como una inmediatez, sino como un riesgo que se corre en un mundo tan pervertido y criminalizado como ese pues, entonces se aprende a moverse con una cierta semiología que yo diría es una semiología derivada del miedo, pero esta tampoco permite que se caiga en el cinismo. Es decir, si tengo miedo no me voy a callar. Entonces te mueves con un semáforo en amarillo, en estado de alerta permanentemente. Hay ciertas fronteras que no se pueden traspasar. 
En un país como Colombia isirve de algo el prestigio internacional?

Pues yo creo que... sirve para la vanidad personal, pero no es válida para los riesgos que conlleva estar metido en el centro de ese escenario. A los actores de la violencia en Colombia se llamen guerrilla, se llamen inteligencia militar del Estado o se llamen paramilitarismo le importa un bledo que tú tengas un prestigio internacional. A lo mejor ni siquiera se dan cuenta que tú tienes ese prestigio.

Volver a España a través de tus novelas como La Muerte de Érika en Espasa Calpe o tú última novela publicada recientemente en Colombia por el sello Seix Barral y que próximamente será editada aquí, ¿qué significa para ti?

Pues, yo no sé lo que significa. Sigue significando publicar un libro y eso que decía Hemingway, el mensaje metido en una botella y lanzado al mar. Mi ausencia relativa del mundo editorial español en doce años ha estado precedida por la presencia de nuevos escritores latinoamericanos, nuevos escritores españoles, con un boom de la literatura española y un neo-boom de la literatura latinoamericana en cuyo centro podría encontrar que hay dos figuras emblemáticas, por un lado la de Bolaño, más joven y por otro la de Sergio Pitol, pero también figuras más mediáticas como la Bryce Echenique y la de Antonio Skármeta. Entonces esa presencia a su vez, está precedida por esas otras presencias poderosas. Algunas de ellas, ya encarriladas en un mercado editorial que tiene unas reglas del juego de juego muy diferentes a las que yo conocí, cuando un libro podía permanecer en las librerías hasta tres o cuatro años. A mí me sucedió con un pequeño libro de cuentos que me publicó Lumen, $A$ golpes, el cual al cabo de algunos años aún estaba en las librerías. Ahora yo no encuentro $\mathrm{La}$ Muerte de Érika y fue publicado hace apenas tres años en una editorial perteneciente a un grupo muy poderoso como es Planeta.

Hay una tendencia por parte de críticos y traficantes de la literatura, de encasillar a los escritores en grupos. Tú llegas a España, en el momento preciso del lanzamiento del llamado boom de la literatura latinoamericana, luego se habló del boom júnior para referirse a escritores como Borges, Sabato o Bioy Casares. Si tuvieses que meterte en alguna de esas casas que se han creado para marcar bien sea a una generación o a una tendencia, ¿donde te meterías? 
Pues no me situaría en ninguna casa. A ver, José Donoso en su bistoria personal del boom me incluye a mí entre otros como quizá, los últimos jóvenes pertenecientes al boom. En realidad, yo me considero más un hijo del boom porque aprendí con grandes escritores del boom, aprendí con Onetti, con Rulfo, incluso con Vargas Llosa cuya cercanía cronológica conmigo apenas lleva una diferencia de cinco, seis años. Pero da la coincidencia histórica de que yo polemicé con el boom y no fueron tanto mis libros de ficción como mis ensayos los que más o menos me hicieron pertenecer de una manera incomoda para mí al boom. Esa es una situación doblemente incomoda porque a la generación siguiente, la que empieza a separarse del boom, le da por pensar que yo no pertenezco a ella y yo, cronológicamente sí pertenezco.

En propio estilo, en mi escritura literaria que ha sido cambiante hay una primera fase que podría perfectamente identificarse con unas ciertas influencias inmediatas del boom, sobre todo de Cortázar y de Vargas Llosa, mezcladas con la formación de un escritor joven que había leído a la gran novela norteamericana sobre todo y luego en los años siguientes una especie de búsqueda de la claridad y de la transparencia a través de formulas narrativas más convencionales, si se quiere más tradicionales. Entonces, una época de experimentación y otra de búsqueda de recuperación de lo clásico. Es ahí donde exista la imposibilidad de meterme en una cualquiera de las casas que se han construido para que nos metamos los que vinimos después del boom. Yo diría que soy una rueda suelta en ese engranaje.

¿Cuál fue tu experiencia personal con los escritores en Barcelona durante aquellos años en que viviste aquî?

Yo era quizá uno de los pocos escritores jóvenes que frecuentaban la tertulia etílica del Bocaccio a principios de los años setenta, donde estaba Rosa Regás que no era escritora entonces, era editora; Beatriz de Moura la creadora de la editorial Tusquets. Entonces estaba Joan Marsé, Gil de Biedma, Enrique Vila-Mata, Carlos Barral, el patriarca José María Castellet, visitaban esa tertulia. De vez en cuando caía Pitol, Jorge Edwars, a veces Donoso o García Márquez.

Como escritor en lengua castellana en Barcelona ite sentías arropado por estos escritores que vivían en Cataluña y que publicaban en castellano? Y ¿de qué manera vivió la intelectualidad el momento en que se lanza desde la Generalitat de Catalunya la política 
cultural de normalización de la lengua catalana en donde, algunos escritores comienzan a ser excluidos por el sólo hecho de publicar en castellano como es el caso de uno de los últimos valores de la literatura española de los años ochenta, Jesús Ferrero?

Lo viví como conflicto porque esa ciudad plural, abierta que vivía con una naturalidad extraordinaria el bilingüismo sin ningún tipo de alteraciones, después, de una manera por un lado explicable, es decir: la recuperación de la lengua, que indudablemente, históricamente había sido excluida y perseguida, pero la recuperación de esa lengua y de ese gran espacio cultural de lo catalán conllevó ciertas ortodoxias y ciertas exclusiones. Empezó a verse mal que escritores nacidos en Barcelona por ejemplo escribieran en castellano. Se comenzaron a dar ciertas inquisiciones alrededor del hecho de que unos Goytisolo escribieran en castellano siendo oriundos de Barcelona, y fue algo extensible a otros como Marsé o Joan Manuel Serrat que también cantaba en castellano. Desconocer que eran charnegos, es decir barceloneses hijos de inmigrantes. En mil novecientos ochenta y nueve cuando me fui, escribí una columna en el Periódico de Cataluña y la escribí como despedida y en ella, manifestaba un poco la incomodidad. Es decir, el mundo que habíamos vivido con una relativa amabilidad, conviviendo catalanes y castellanos, era un mundo que se iba volviendo cada vez más sectario y a mirarnos despectivamente, como intrusos a los castellano parlantes, a los castellano escribientes. Esa sensación la compartíamos escritores que más o menos empezamos a irnos en ese momento, como José Donoso, como Edwars, y...mi regreso a Colombia coincide con ese momento de crispaciones que dieron comienzo sí, un gran proceso y un importante proceso de recuperación de la cultura y de la lengua catalana, no sólo en el mundo editorial, sino en la enseñanza, pero también en la actitud de exclusión y de resentimiento frente a aquello que había estado ahí en toda la historia de la ciudad de Barcelona, que era la convivencia. Barcelona es una ciudad mestiza. La industria de esta ciudad se hace sobre los lomos de los andaluces, de los gallegos, etc. que hoy, son una cuarta generación de catalanoparlantes, pero que fueron la mano de obra excluida en su momento, cuando a principios del siglo $\mathrm{XX}$ se monta la industria catalana.

En cierta ocasión leí que García Márquez siempre habła querido escribir un bolero y que a pesar de haber recibido los mejores con- 
sejos de Armando Manzanero y de Silvio Rodríguez, nunca lo había conseguido, lo que para Gabo, queda como esa cosa pendiente con un genero literario: el bolero.

Yo te quiero glosar esa cosa que acabas de decir sobre García Márquez. El no tiene que sentirse frustrado por no haber escrito un bolero, porque yo creo que hay un gran bolero clásico en su obra y es El amor en los tiempos del cólera. Es el tema de un bolero: un par de amantes que se distancian, que aplazan el momento de la copula final. Además, escribió un gran ballenato que es Cien años de soledad. Yo creo que él no ha caído en la cuenta y está bien que lo hablemos porque se lo pienso decir. Además, Gabo dice y muchos lectores estamos de acuerdo con él, que su gran novela no es Cien años de soledad, la gran novela es El amor en los tiempos del cólera y sabes por qué, porque en está última hay una construcción de personajes y hay una gran épica del amor, lo otra novela es un mural, la épica metafórica de la gran fundación de América, es las Hojas de hierba de Witman, es El canto general de Neruda, es la gran épica donde no hay singularizado una conducta humana. La condición humana aparece en arquetipos, pero en la otra hay personajes de carne y hueso.

¿Crees que volveremos a la novela que nos hable de la finca, de lo rural sin el temor de ser tachados de garciamaquianos?

En los años sesenta había una especie de inquisición que se derivaba de una falsa alternativa: literatura rural o literatura urbana, solamente era bueno el escritor joven que escribía sobre la ciudad. Lo otro, era un escritor del pasado, que escribía sobre el campo. La respuesta a ese falso dilema la dio Rulfo y de alguna manera también García Márquez. Es decir, era un falso antagonismo. En Colombia hay un debate entre los jóvenes escritores, esta nueva generación que incluso tiene una presencia internacional a través de los nuevos sistemas de contratación editorial y acaban de hacer ser invitados a la Feria del Libro de Buenos Aires y estaba leyendo en el último número de la revista Semana en la sección de cultura que todos ellos renegaban de García Márquez, pero dime tú, para qué van a matar a un padre que no ha ejercido ningún tipo de autoridad sobre ustedes. Digan sencillamente que García Márquez representa un modelo de literatura que no les interesa, porque la sensibilidad de ustedes se ha movido entre la inmediatez de lo urbano, entre las tensiones y la 
esquizofrenia del mundo urbano. Pero tratar de matar a García Márquez, cuando a él le complace que ustedes estén escribiendo sobre aquello que escriben, me parece una solemne tontería. No se inventen un padre tiránico donde ha existido un abuelo generoso.

¿Qué autor ha ejercido sobre Óscar Collazos algún tipo de influencia de la manera que lo ha hecho William Faulkner en Vargas Llosa, García Márquez y Onetti?

Para mí, fue una gran revelación haber leído a los dieciocho años a John D. Sanlinger y en especial su libro El Guardián en el centeno que lo había leído en una edición argentina bajo el título El Cazador oculto (The Catcher in the Rye). ¿Sabes por que fue una gran revelación? Porque me di cuenta que hablar desde la autobiografía de un adolescente o desde la niñez, eso era perfectamente licito, que pertenecía a un mundo que no era el mundo rural y mítico de Faulkner, ni siquiera el de García Márquez. Mi infancia y adolescencia transcurren en un puerto. Los puertos por pequeños que sean, son el mayor de los símbolos de cosmopolitismo. Entonces con Salinger, descubrí que era posible hablar de la adolescencia y del disgusto y del encabronamiento que todo adolescente tiene sobre las estructuras familiares inmediatas: sobre el principio de la autoridad, sobre la moral, sobre el sexo. Así, fue como una apertura y una legitimación de aquello que yo quería hacer. García Márquez dice que él empezó a escribir con una gran libertad cuando leyó la primera frase de La metamorfosis de Kafka.

¿Alguna droga mayor que la combinación de droga, sexo, el ron, puesta de sol en las playas del Caribe, rumba?

Las mujeres. 